\title{
Estado, tierra y poblamiento en la campaña sur de Buenos Aires durante la época de Rosas. La frontera del arroyo Azul*
}

\author{
María Sol Lanteri \\ Universidad de Buenos Aires/CONICET
}

Este trabajo trata de contribuir al conocimiento de la política de tierras desarrollada por el Estado provincial de Buenos Aires en la primera mitad del siglo XIX, especialmente durante el gobierno de Rosas. A través del análisis del impacto micro-regional de la política central en un estudio de caso, el de la frontera de Azul, se discute la tesis historiográfica que tradicionalmente consideró al rosismo como el creador de una estructura agraria latifundista en la frontera sur bonaerense. Por el contrario, el estudio de Azul muestra el predominio de unidades de propiedad y de producción rurales de pequeñas-medianas dimensiones que coexistieron con otras de gran tamaño.

Palabras ClaVe: Estado provincial de Buenos Aires, rosismo, frontera sur- política de tierras, poblamiento.

This paper tries to contribute to the knowledge of the land policy developed by the provincial State of Buenos Aires in the first half of the nineteenth century, specially during the Rosas government. Throughout the analysis of the micro-regional impact of the central policy in a case study, the frontier of the Azul brook one, it is discussed the historiographical thesis that has traditionally considered the Rosas government as the forger of an agrarian structure of large entailed estate in the south frontier of Buenos Aires. On the contrary, the study of Azul shows the predominance of rural property and production unities of small and medium size, which have coexisted with others of big one.

KEYWORDS: provincial State of Buenos Aires, Rosas government, south frontier, land policy, settlement.

La ruptura del orden virreinal causada por las guerras de la independencia en el Río de la Plata así como en otras regiones de América produjo grandes transformaciones en sus aspectos político, económico, social y

* Este artículo forma parte de un proyecto de investigación, cuyo objetivo final es la realización de mi tesis doctoral en Historia financiada por una beca interna de postgrado tipo I libre del CONICET que dirige el Dr. Jorge Gelman (Instituto Ravignani-UBA/CONICET) y constituye un resumen modificado del trabajo de investigación final "Estado, tierra y poblamiento en América meridional. La colonización de la frontera sur bonaerense durante la primera mitad del siglo XIX", 
cultural. El vacío de poder centralizado que sufrieron las ex colonias se vio reemplazado por diferentes formas de organización político-institucional que, en el caso rioplatense, favoreció que aparecieran los Estados provinciales hasta el proceso de centralización del Estado argentino hacia fines del siglo XIX.

De esta forma, durante la primera mitad de ese siglo, los distintos Estados provinciales del litoral y del interior, constituidos por antiguas ciudades-provincias coloniales y su hinterland rural, articularon diversos pactos y tratados que cristalizaron en el surgimiento de la Confederación Argentina liderada especialmente por los caudillos del primer ámbito. Entre éstos, Juan Manuel de Rosas, gobernador de la provincia de Buenos Aires durante el período 1829-1852, con un intervalo de tres años comprendido entre 1832-1835, fue la figura política que logró mantenerse en el poder provincial y que contribuyó a la hegemonía del Estado porteño hasta su derrocamiento en $1852 .^{2}$

En gran medida, la historiografía consideró tradicionalmente que el surgimiento y la consolidación de los caudillos rioplatenses y americanos estuvieron estrechamente vinculados con el grupo de los grandes terratenientes, con los cuales se identificaron y sustentaron las bases de su poder político y económico en detrimento del resto de la población rural. La polí-

\footnotetext{
I Máster de Especialización en Historia Iberoamericana, IH-CSIC, Madrid, 2003, que fue realizada bajo la tutoría de la Dra. Elda E. González Martínez merced a una beca otorgada por la Fundación Carolina. Agradezco muy especialmente al Dr. Jorge Gelman, a la Dra. Elda González (CSIC, Madrid), al Lic. Javier Bravo García (Fundación Histórica Mafre-Tavera) y a la Dra. Pilar González Bernaldo (Université Paris 7) por su generosa ayuda prestada durante mi estancia en Madrid y al primero además por sus comentarios a una versión preliminar. Asimismo, al grupo Historiar por su colaboración en la recolección de parte del material documental y al Dr. Guillermo Banzato (UNLP/CONICET) y al Dr. Eduardo Míguez (UNICEN/UNMdP) por sus comentarios y bibliografía.E-mail: sol_lanteri@ciudad.com.ar

1 Sábato, Hilda (Coord.): Ciudadanía política y formación de las naciones. Perspectivas históricas de América Latina, El Colegio de México, Fondo de Cultura Económica, México, 1999. Irigoin, María Alejandra; Schmit, Roberto (Eds.): La desintegración de la economía colonial. Comercio y moneda en el interior del espacio colonial (1800-1860), Biblos, Buenos Aires, 2003. Chiaramonte, José Carlos: Mercaderes del Litoral. Economía y sociedad en la provincia de Corrientes, primera mitad del siglo XIX, Fondo de Cultura Económica, México- Buenos Aires, 1991 y Ciudades, provincias, Estados: Orígenes de la Nación Argentina (1800-1846), Ariel Historia, Buenos Aires, 1997. Halperín Dongui, Tulio: Revolución y guerra. Formación de una elite dirigente en la Argentina criolla, Siglo XXI, Buenos Aires, 1972. Oszlak, Oscar: La formación del Estado argentino. Orden, progreso y organización nacional, Planeta, Buenos Aires, 1997.

2 Chiaramonte: Mercaderes... Halperín Donghi, Tulio: De la Revolución de Independencia a la Confederación Rosista, Historia Argentina 2, Paidós, Buenos Aires, 1998, págs. 13-413. Lafforgue, Jorge (Ed.): Historias de caudillos argentinos, Punto de lectura, Buenos Aires, 2002.
} 
tica de tierras implementada por ellos habría contribuido a generar la presencia de grandes latifundios, especialmente en las zonas de la nueva frontera interna, y de este modo, habría beneficiado al sector social de los grandes propietarios, a diferencia de lo ocurrido en otros procesos colonizadores, como el de Estados Unidos o Canadá, donde la presencia de los pequeños y medianos propietarios tuvo un papel destacado. ${ }^{3}$

En el caso particular de Rosas, el desarrollo de una política de cesiones de tierras públicas a manos de particulares basada en el otorgamiento de premios a la fidelidad política o por campañas militares contra los indios, donaciones incondicionadas y condicionadas y la venta de 1.500 leguas cuadradas ${ }^{4}$ en el sur de la provincia de Buenos Aires fue considerado por sus detractores políticos como política dilapidadora de los recursos fiscales a discreción del gobernador y generadora de una estructura agraria latifundista en la frontera sur que benefició a los amigos del "régimen" y que originó posteriores procesos sucedidos en la "Argentina moderna". ${ }^{5}$

De hecho, hasta bien avanzado el siglo XX, la mayor parte de la historiografía rural argentina homologó la historia nacional casi exclusivamente con el espacio pampeano bonaerense, extrapolando cronológicamente los resultados de los procesos históricos de finales del siglo XIX - como la gran expansión agraria vinculada al sector externo y la forma-

3 Lynch, John: Juan Manuel de Rosas, Emecé, Buenos Aires, 1997 y Caudillos en Hispanoamérica, 1800-1850, Mapfre, Madrid, 1993. Oddone, Jacinto: La burguesía terrateniente argentina, Libera, Buenos Aires, 1967. Carretero, Andrés: La llegada de Rosas al poder, Pannedille, Buenos Aires, 1971 y La propiedad de la tierra en la época de Rosas, Coloquio, Buenos Aires, 1972, entre otros. Sobre la colonización de Norteamérica véase Adelman, Jeremy; Stephen, Aaron: "From borderlands to borders. Empires, nation states and the peoples in between in North American History", The American Historical Review, Vol. 104, N³, 1999, págs. 814-841. White, Richard: "It's your misfortune and none of my own". A New History of the American West, University of Oklahoma Press, Norman and London, 1991. Álvarez Maurín, María José: "Las praderas fronterizas de Canadá y Estados Unidos", en Álvarez Maurín, María José; Broncano, M.; Chamosa, J. L. (Coords.): La frontera. Mito y realidad del Nuevo Mundo. Actas del Congreso celebrado en la Universidad de León los días 13 al 17 de septiembre de 1993, Universidad de León, España, págs. 115-122. Una revisión historiográfica en Ratto, Silvia: "El debate de la frontera a partir de Turner. La New Western History, los Borderlands y el estudio de las fronteras latinoamericanas", Boletín del Instituto de Historia Argentina y Americana “Dr. Emilio Ravignani”, Tercera Serie, 24, Buenos Aires, 2003. págs. 105-126.

4 Cada legua cuadrada era equivalente a 2.700 hectáreas (en adelante has.) hasta 1881 y cada hectárea a 10.000 metros cuadrados.

5 Oddone: La burguesía... Carretero: La propiedad... y "Contribución al conocimiento de la propiedad rural en la Provincia de Buenos Aires para 1830", Separata del Boletín del Instituto de Historia Argentina “Dr. Emilio Ravignani”, Tomo XIII, 2a serie, 22-23, Buenos Aires, 1970, entre otros. 
ción de una "clase terrateniente"- al período tardo-colonial, incluso aquellos supuestos provenientes de otras regiones de Hispanoamérica como el norte de México. De esta forma, sucesos históricos relevantes en un país de tradición agro-exportadora como la Argentina, como el acceso a la tierra y las relaciones sociales de producción, se explicaban mediante una visión que destacaba una estructura socio-económica y política simple, basada en la omnipresencia del gran latifundio ganadero extensivo desde la colonia tardía, es decir, amplias extensiones de tierras concentradas en manos de unos pocos particulares en propiedad plena, estrechamente relacionados e identificados con los gobiernos de turno, que mantenían lazos cuasi feudales con la fuerza de trabajo de sus estancias, los peones, varones solos sin familia, cuya producción principal era la ganadería vacuna orientada al mercado externo. ${ }^{6}$

Empero, basados en una nueva documentación, estudios recientes sobre el mundo rural rioplatense han develado renovados problemas, enfoques y metodologías: Ha surgido así una visión mucho más compleja y diversificada de este espacio en sus diferentes aspectos, que plantean rupturas y continuidades entre los períodos tardo-colonial e independiente, y comprueba, en contraste con este modelo tradicional, la existencia de unidades de propiedad y de producción agraria mixta y diversificada de distinto tamaño, con mano de obra libre y esclava con una presencia importante de la familia, orientada tanto a mercados externos como regionales y locales desde finales del siglo XVIII, así como la autonomía entre los procesos de formación de la "clase terrateniente" y del Estado. En lo referente al acceso y tenencia de la tierra, demuestran que ésta fue el factor de producción más abundante en la campaña desde ese período, así como plantean los diversos ritmos en la constitución de un mercado de tierras, diferencias regionales basadas en la antigüedad de asentamiento, las múltiples formas de acceder al recurso que excedieron sustancialmente a la

6 Una puesta al día sobre estas posturas historiográficas en Míguez, Eduardo: "La expansión agraria de la pampa húmeda (1850-1914). Tendencias recientes de su análisis histórico", Anuario del IEHS, 1, UNCPBA, Tandil, 1986, págs. 89-119. Un trabajo pionero que discutió estos planteos fue el de Halperín Donghi, Tulio: "La expansión ganadera en la campaña de Buenos Aires (1810-1852), Desarrollo Económico, Vol. 3, Buenos Aires, abril-septiembre de 1963, págs. 57-110. Sobre la evolución de los estudios de la hacienda hispanoamericana véase Mörner, Magnus: "La hacienda hispanoamericana en la Historia: un esquema de reciente investigación y debate", Desarrollo Económico, Vol.13, 52, Buenos Aires, enero-marzo de 1974, págs. 741-773 y Van Young, Eric: "Mexican Rural History since Chevalier: The Historiography of the Colonial Hacienda", Latin American Research Review, Volume XVIII, 3, 1983, págs. 5-61. 
propiedad privada plena (ocupación sin títulos legales, arrendamiento, etc.), la coexistencia de superficies de variados tamaños, la diversidad de actores sociales que intervienen y la importancia de las prácticas consuetudinarias de una población de índole campesina en el proceso de implantación regional del sistema capitalista y la constitución del Estado independiente que, lejos de haber sido lineales, no estuvieron exentos de conflictos. ${ }^{7}$

En consonancia con estos avances de la producción de las últimas décadas, tanto la política de tierras efectuada por el gobierno de Rosas, como muchas otras cuestiones concernientes a los caudillismos rioplatenses, la articulación de su poder, la importancia de los pequeños-medianos productores y propietarios rurales en su sustento, la relación con las formas y prácticas institucionales y de legalidad política, el rol de los sectores subalternos, entre otras son objeto de una revisión historiográfica, que se plantea nuevas miradas, iluminando un tema medular en la historia americana de ese momento. ${ }^{8}$ De esta forma, nuevas investigaciones que analizaron la política de premios y donaciones incondicionadas otorgada por el rosismo a manos de particulares han demostrado que no tuvo las dimensiones que sus opositores políticos contemporáneos estimaron y que manifestó una

7 Un estado de la cuestión sobre los estudios rurales de la campaña rioplatense en Garavaglia, Juan Carlos; Gelman, Jorge: "Mucha tierra y poca gente: un nuevo balance historiográfico de la historia rural platense (1750-1850)", Historia Agraria, 15, Revista Semestral del Seminario de Historia Agraria, Murcia, enero-junio de 1998, págs. 29-50 y Fradkin, Raúl; Gelman, Jorge: "Recorridos y desafíos de una historiografía. Escalas de observación y fuentes en la historia rural rioplatense", en Bragoni, Beatriz (Edit.): Microanálisis. Ensayos sobre historiografía argentina, Prometeo, Buenos Aires, 2004, págs. 31-54.

8 Véase especialmente Goldman, Noemí; Salvatore, Ricardo (Comps.): Caudillismos rioplatenses. Nuevas miradas a un viejo problema, Eudeba, Buenos Aires, 1998 y Goldman, Noemí (Dir.): Nueva Historia Argentina. Revolución, República, Confederación (1806-1852), Sudamericana, Buenos Aires, 1998. Nuevas perspectivas de historia política del siglo XIX en Sábato, Hilda; Lettieri, Alberto (Comps.): La vida política en la Argentina del siglo XIX. Armas, votos y voces, Fondo de Cultura Económica, Buenos Aires, 2003 y Sábato, Hilda: La política en las calles. Entre el voto y la movilización. Buenos Aires, 1862-1880, Sudamericana, Buenos Aires, 1998. Quijada, Mónica; Bernand, Carmen; Schneider, Arnd: Homogeneidad y Nación con un estudio de caso: Argentina, siglos XIX y XX, Colección Tierra Nueva e Cielo Nuevo, 42, CSIC, Madrid, 2000. Ternavasio, Marcela: La revolución del voto. Política y elecciones en Buenos Aires, 1810-1852, Siglo XXI, Buenos Aires, 2002. Bragoni, Beatriz: Los hijos de la revolución. Familia, negocios y poder en Mendoza en el siglo XIX, Taurus, Buenos Aires, 1999. Romano, Silvia: Economía, sociedad y poder en Córdoba. Primera mitad del siglo XIX, Ferreyra Editor, Córdoba (Argentina), 2002. Para el caso latinoamericano ver la compilación de Sevilla Soler, Rosario (Comp.): Consolidación republicana en América Latina, Escuela de Estudios Hispano-Americanos, CSIC, Sevilla, 1999 y Peralta Ruiz, Víctor; Irurozqui Victoriano, Marta: Por la concordia, la fusión y el unitarismo. Estado y caudillismo en Bolivia, 1825-1880, Colección Tierra Nueva e Cielo Nuevo, 41, CSIC, Madrid, 2000. 
envergadura mucho menor que la planteada tradicionalmente, debido a que no todas las personas - beneficiadas por ella - realizaron la correspondiente escritura para apropiarse de las tierras. ${ }^{9}$

A pesar de analizar las modalidades de cesiones de tierras fiscales a manos de particulares desarrolladas por el gobierno rosista en el marco del proceso de apropiación privada de tierras públicas en la provincia de Buenos Aires, hasta el momento no se ha considerado el impacto cuantitativo de otra forma de traspaso como fueron las donaciones condicionadas de tierras en propiedad cedidas a partir de 1829. En efecto, a partir de ese momento, siendo Viamonte el gobernador provisorio de la provincia de Buenos Aires y amparado por Rosas, el Estado dispone la cesión de tierras fiscales en distintas regiones de frontera, pero sólo se efectivizan en la zona del arroyo Azul, aunque no fue estipulado el monto de la oferta estatal. Estas donaciones de tierras fueron condicionadas porque su efectiva apropiación legal a partir de la escrituración estaba sujeta al cumplimiento de una serie de disposiciones de poblamiento y defensa de la frontera por parte de los beneficiados. ${ }^{10}$

Ahora bien, si, como los estudios agrarios recientes han demostrado, la tierra era el factor de producción más abundante en la campaña rioplatense desde la época tardo-colonial, ¿por qué se donaron tierras fiscales en Azul? ¿Cuáles fueron las características centrales del proceso y cuál la envergadura de esta política comparada con otras modalidades implementadas en la región? El objetivo central de este trabajo será entonces tratar de contribuir a saldar estos interrogantes mediante el análisis del impacto micro-regional que tuvo la política central de tierras desarrollada por el Estado provincial de Buenos Aires durante el período 1820-1860; es decir, desde el mismo momento de su conformación hasta casi inclusive una década después de la caída del rosismo. ${ }^{11}$ De esta forma, nos centraremos

9 Infesta, María Elena; Valencia, Marta. E.: "Tierras, premios y donaciones. Buenos Aires: 1830-1860”, Anuario del IEHS, 2, UNCPBA, Tandil, 1987, págs. 177-211. Infesta, María Elena: La pampa criolla. Usufructo y apropiación privada de tierras públicas en Buenos Aires, 1820-1850, Publicaciones del Archivo Histórico de la provincia de Buenos Aires, La Plata, 2003.

10 Infesta: La pampa criolla...; Infesta, María Elena: "Propiedad rural en la frontera. Azul, 1839”, en Barba, Enrique: In Memoriam. Estudios de Historia, Edición Banco Municipal de La Plata, Buenos Aires, 1994, págs. 269-286.

11 Cabe destacar que a partir de 1852 el Estado de Buenos Aires se separa de la Confederación Argentina, integrada por el resto de los Estados del litoral y del interior, hasta el año de 1861 en que comienza a formar parte de la misma. Por otro lado, no consideramos la parte urbana del partido por exceder los límites de nuestro trabajo. 
en la relevancia que tuvieron las donaciones en esa zona de la frontera sur bonaerense y mostraremos asimismo las distintas modalidades de traspaso de tierras públicas, haciendo hincapié en la importancia que tuvo el gobierno rosista en el poblamiento y en la creación de distintos grupos de tenedores de tierras en la región.

Para ello comenzaremos por recordar las políticas colonizadoras efectuadas por el Estado en el Río de la Plata desde la época tardo-colonial; luego, las particularidades del período rosista, el marco legal de las donaciones y las características de su proceso de poblamiento. En un segundo apartado, nos centraremos en el análisis de las cesiones de tierras fiscales en Azul tratando de reconstruir el volumen de las donaciones comparado con otras modalidades de otorgamiento y, finalmente, esbozaremos algunas conclusiones que se desprendan de nuestro trabajo.

Como mostraremos, la tesis que tradicionalmente consideró al rosismo como el forjador de una estructura agraria latifundista en la frontera sur se advierte nuevamente relativizada en el marco de su coexistencia con otras unidades de propiedad y de producción de menores dimensiones, que fueron predominantes en Azul, a diferencia de lo ocurrido en otros partidos de la campaña de Buenos Aires. Estas donaciones condicionadas de tierras de pequeñas-medianas superficies adjudicadas por el gobierno de Rosas se las enmarca en un proceso de expansión económica basado especialmente en el ciclo del vacuno y en una crítica coyuntura histórica de consolidación de la soberanía territorial del Estado provincial en el "nuevo sur" bonaerense, durante la cual se estaba fortaleciendo además el poder de un nuevo sector dirigente y propietario en el litoral: la facción rosista del federalismo porteño. ${ }^{12}$

Las fuentes que utilizamos constituyen la totalidad del corpus documental de los duplicados de diligencias de mensuras de Azul del Archivo Histórico de la Dirección de Geodesia y Catastro de la provincia de Buenos Aires (DGYC), formado por 436 documentos; todos los expedientes sobre tierras en usufructo de Azul hasta 1860 de la Escribanía Mayor de Gobierno del Archivo Histórico de la Provincia de Buenos Aires (AHP-

12 Véase Garavaglia, Juan Carlos: "La propiedad de la tierra en la región pampeana bonaerense: algunos aspectos de su evolución histórica (1730-1863)”, en Fradkin, Raúl O.; Garavaglia; Juan Carlos (Edits): En busca de un tiempo perdido. La economía de Buenos Aires en el país de la abundancia, 1750-1865, Prometeo Libros, Buenos Aires, 2004, págs. 65-106 y Gelman, Jorge: "Unitarios y federales. Control político y construcción de identidades en Buenos Aires durante el primer gobierno de Rosas", Anuario IEHS, 19, UNCPBA, Tandil, 2004, págs. 359-390. 
BA), el informe sobre las suertes del sargento Cornell de 1859 (DGYC) y otras complementarias, como padrones, informes de agrimensores y recursos cartográficos de la región.

\section{La colonización de la frontera sur bonaerense: el poblamiento y las políticas del Estado}

Durante los tres siglos de dominación colonial el espacio, efectivamente controlado por la monarquía española y la sociedad "hispano-criolla" en el Río de la Plata, llegaba hasta el llamado "corredor porteño"; es decir, una pequeña porción del territorio que actualmente constituye la provincia de Buenos Aires, formada por la ciudad homónima, capital del virreinato del Río de la Plata desde 1776, y sus zonas rurales aledañas, cuya producción se orientaba especialmente al abastecimiento de mercados regionales en torno al eje comercial Potosí-Interior-Buenos Aires que la producción de plata articuló. ${ }^{13}$ El río Salado, la cuenca hidrográfica más extensa del lugar, fue el límite natural establecido con las sociedades indígenas asentadas en la región durante la colonia, aunque no impidió el desarrollo de relaciones interétnicas asiduas. ${ }^{14}$

Si bien a partir de la segunda fundación de Buenos Aires en 1580 comenzó a desarrollarse la expansión de su hinterland agrario con la formación de las primeras chacras trigueras en su entorno, la frontera sur bonaerense se ocuparía paulatinamente desde 1720 hasta 1852, tanto de forma espontánea, con el asentamiento de colonos nucleados en torno a capillas u otros centros, como de forma forzosa, mediante la política estatal de poblamiento de la frontera con el indígena, para ocuparla, mantenerla y controlarla de forma más sistemática. ${ }^{15}$ A partir de 1820, el Estado pro-

13 Halperín Donghi: De la Revolución... Assadourian, Carlos Sempat: El sistema de la economía colonial, Nueva Visión, México, 1984.

14 Mandrini, Raúl: "Guerra y Paz en la frontera bonaerense durante el siglo XVIII", Ciencia Hoy, Vol. 4, 23, Buenos Aires, marzo-abril de 1993, págs. 26-35 y "Las fronteras y la sociedad indígena en el ámbito pampeano", Anuario del IEHS, 12, UNCPBA, Tandil, 1997, págs. 23-34. León Solís, Leonardo: Maloqueros y Conchavadores en la Araucanía y las Pampas, 1700-1800, Ediciones Universidad de la Frontera, Londres, 1991.

15 Garavaglia, Juan Carlos: Pastores y labradores de Buenos Aires. Una historia agraria de la campaña bonaerense 1700-1830, Ediciones de la Flor, Buenos Aires, 1999, especialmente cap. I "La pampa” y cap. II "Hombres y mujeres", págs. 36-51. 
vincial de Buenos Aires comenzó un proceso de expansión hacia el sur, territorio ocupado por los indígenas desde los albores del asentamiento humano en la región, para afianzar su dominio en el lugar y acaparar esas tierras y poder articularlas al nuevo marco productivo, fundamentalmente ganadero, que estaba produciéndose en aquel entonces. ${ }^{16}$ Este nuevo ciclo económico, que contribuyó a la inserción de la economía rioplatense al mercado internacional, junto con los cambios producidos en la coyuntura post-revolucionaria, generaron una transformación en la elite rioplatense que, de caracterizarse por sus actividades mercantiles desde la época colonial, comenzó a invertir en tierras y en la actividad pecuaria, aunque manteniendo su interés en el sector urbano. ${ }^{17}$

El avance oficial hacia el sur no fue novedoso en el contexto rioplatense. Ya desde la época tardo-colonial, el Estado había tenido la intención de fundar centros de avanzada de población civil, inclusive al sur del río Salado, además de implementar otros métodos como la línea de fortines o el mantenimiento de cuerpos militares regulares para disputar la frontera con el indígena. Cabe citar los planes del virrey Vértiz o de Félix de Azara; o más tardíamente los de Pedro Andrés García, que por diversas causas parecen no haberse concretado. ${ }^{18}$ Sin embargo, la imposibilidad estatal en controlar de forma efectiva este territorio no impidió que simultánea o anticipadamente al accionar del Estado, los pobladores del interior del virreinato del Río de la Plata, de diferentes zonas de la campaña e inmigrantes extranjeros fueran asentándose en diversas regiones, poniendo en produc-

16 Halperín Donghi: "La expansión ganadera...".

17 Halperín Dongui: "La expansión ganadera...". Halperín Donghi: Revolución y guerra... y "Clase terrateniente y poder político en Buenos Aires (1820-1930)", Cuadernos de Historia Regional, Universidad Nacional de Luján, Buenos Aires, $2^{\circ}$ semestre de 1992, págs. 11-45. Garavaglia: Pastores y labradores... y "Patrones de inversión y 'elite económica dominante': los empresarios rurales en la pampa bonaerense a mediados del siglo XIX", en Gelman, Jorge; Garavaglia, Juan Carlos; Zeberio, Blanca (Comps.): Expansión capitalista y transformaciones regionales. Relaciones sociales y empresas agrarias en la Argentina del siglo XIX, La Colmena, Buenos Aires, 1999, págs. 121-143. Hora, Roy: Los terratenientes de la pampa argentina. Una historia social y política 1860-1945, Siglo XXI, Buenos Aires, 2002. Barsky, Osvaldo; Djenderedjian, Julio: Historia del capitalismo agrario pampeano. La expansión ganadera hasta 1895, Tomo 1, Universidad de Belgrano, Siglo XXI, Buenos Aires, 2003.

18 Marfany, Roberto: El indio en la colonización de Buenos Aires, Comisión Nacional de Cultura, Buenos Aires, 1940, caps. III y IV, págs. 67-106. Barros, Alvaro: Fronteras y territorios federales de las pampas del sud, Colección "El pasado argentino", Hachette, Buenos Aires, 1975, cap. V, págs. 143-155. Gelman, Jorge: Un funcionario en busca del estado. Pedro Andrés García y la cuestión agraria bonaerense, 1810-1822, Universidad Nacional de Quilmes, Buenos Aires, 1997. 
ción y estableciendo distintas relaciones jurídicas con la tierra que ocuparon desde ese momento. ${ }^{19}$

Empero, lo novedoso de este proceso en la coyuntura post-independiente fue el avance exitoso, aunque con retrocesos, del Estado porteño en la frontera sur mediante la fundación de pueblos, fortines, la extensión de la ciudadanía política y la incorporación definitiva de este territorio al "Estado Nacional" hacia fines del siglo XIX.$^{20}$ Entre las distintas políticas formales implementadas, la de tierras tuvo una gran relevancia, porque permitió, entre otras cuestiones, el establecimiento de una población, su puesta en producción y su apropiación legal, a ritmos no necesariamente concomitantes, a la vez que la canalización de ingresos al Estado mediante el pago de cánones o de ventas.

En este sentido, durante la primera mitad del siglo XIX se destacan dos oleadas de ocupación y apropiación legal de las tierras fiscales en la campaña de Buenos Aires. La primera, comprendida por las grandes extensiones donadas por el Directorio hasta 1820, que continuaban las mercedes coloniales, a particulares en diferentes regiones de la campaña, y la segunda, por la modalidad de la enfiteusis, implementada desde 1822 hasta 1840, mediante la cual el Estado traspasaba a particulares el usufructo de grandes superficies de tierras a un bajo costo, que permanecían en manos oficiales

19 Ver entre otros Mateo, José: "Migrar y volver a migrar. Los campesinos agricultores de la frontera bonaerense a principios del siglo XIX”, en Garavaglia, Juan Carlos; Moreno, José Luis: Población, sociedad, familia y migraciones en el espacio rioplatense. Siglos XVII y XIX, Cántaro, Buenos Aires, 1993, págs. 123-148. Canedo, Mariana: "Tierra sin gente y gente con tierra. La dinámica del acceso y de la transferencia de la tierra en una zona de colonización temprana de la campaña de Buenos Aires. (Los Arroyos, 1600-1850)", en Zeberio, Blanca; Bjerg, María; Otero, Hernán (Comps.): Reproducción social y sistemas de herencia en una perspectiva comparada. Europa y los Países Nuevos (siglos XVIII al XX), IEHS, Tandil, 1998, págs. 83-119. Banzato, Guillermo: "Ocupantes y propietarios legales en la región noreste del río Salado. Chascomús, Ranchos y Monte entre 1779 y 1850", en Girbal-Blacha, Noemí; Valencia, Marta (Coords.): Agro, tierra y política. Debates sobre la historia rural de Argentina y Brasil, Editorial de la Universidad Nacional de La Plata, Buenos Aires, 1998, págs. 37-64. Fradkin, Raúl: “'Según la costumbre del Pays’: costumbre y arriendo en Buenos Aires durante el siglo XVIII", Boletín del Instituto de Historia Argentina y Americana "Dr. Emilio Ravignani”, Tercera Serie, 11, Buenos Aires, 1995, págs. 39-64. Mascioli, Alejandra: "Caminos de acceso al usufructo y propiedad legal de la tierra en la frontera bonaerense. Dolores, 1798-1860", Quinto Sol, Revista de Historia Regional, 6, 6, Instituto de Estudios SocioHistóricos, Facultad de Ciencias Humanas, Universidad Nacional de La Pampa, Argentina, 2002, págs. 69-106.

20 Cansanello, Carlos: "De súbditos a ciudadanos. Los pobladores rurales bonaerenses entre el Antiguo Régimen y la Modernidad", Boletín del Instituto de Historia Argentina y Americana "Dr. Emilio Ravignani”, Nº11, Tercera Serie, Buenos Aires, 1995, págs. 113-139 y "Pueblos, lugares y fronteras de la provincia de Buenos Aires en la primera parte del siglo XIX", Jahrbuch Für Geschichte Lateinamerikas 35, Böhlau Verlag Köln Weimar Wien, Alemania, 1998, págs. 159-187. 
siendo garantía de préstamos externos. ${ }^{21}$ Es en este marco y dentro del proceso de expansión hacia las tierras del "nuevo sur" cuando se puebla la zona del arroyo Azul que, a diferencia de otras regiones de la campaña bonaerense, se destaca porque su proceso colonizador fue impulsado por el Estado provincial mediante una serie de donaciones condicionadas de suertes de estancia en propiedad otorgadas en 1829 , que se efectivizan a partir de $1832 .{ }^{22}$

Cabe destacar que la zona que denominamos del arroyo Azul comprendía en ese momento una extensión mayor a la que adquiriría el partido homónimo hacia finales del siglo XIX. De hecho, según el informe que realiza el sargento Cornell en 1859, las suertes de estancia estaban ubicadas en “...una estencion de campo a una y otra vanda del espresado Arroyo [Azul, SL] cuya longitud yo la calculo en mas de treinta leg. partiendo desde el Gualicho a las lagunas de Artalejo entre Tapalque y los Huesos. Toda la parte occidental de esa longitud ha sido y es frontera", ${ }^{23}$ a lo que habría que adicionar otras tierras en usufructo y en propiedad (ver mapa 1). En la segunda mitad del siglo y conforme se fueron creando nuevos partidos como Juárez en 1867, Olavarría en 1878 y estableciendo los límites precisos de los otros colindantes, los de Azul se fueron reduciendo hasta alcanzar aproximadamente los actuales. ${ }^{24}$

Las donaciones condicionadas constituyeron una modalidad singular establecida desde el Estado provincial, porque a pesar de que ya había habido asignaciones de tierras realengas o públicas a manos de particulares desde la época colonial, su entrega no había sido tan sistemática y concentrada geográficamente como las del arroyo Azul, además de presentar un tamaño medio mucho más reducido. ${ }^{25}$ Estas concesiones parecen haber sido las primeras de una serie de repartos de tierras que continuó en otros lugares de la campaña bonaerense a partir de entonces, como en Chacarita, San

21 Infesta, María Elena: "Estrategias de apropiación privada de tierras nuevas en Buenos Aires en la primera mitad del siglo XIX", en Girbal-Blacha: Agro, tierra y política..., págs. 21-35 y "La enfiteusis en Buenos Aires. 1820-1850”, en Bonaudo, Marta; Pucciarelli, Alfredo (Comps.): La problemática agraria. Nuevas aproximaciones, Vol. 1, CEAL, Buenos Aires, 1993, págs. 93-120.

22 Infesta: "Propiedad rural en la frontera...".

23 DGYC, La Plata: "Informe dirigido al Sor Ministro de Gobierno en el que se da cuenta haber desempeñado Don Juan Cornell la comisión de que fue encargado para el Partido Arroyo Azul”, en Libros de Suertes del Arroyo Azul 1832-1880, Dirección de Geodesia, Asesoría Histórica, 162 (bis), La Plata, 1859, pág. 3.

24 Ronco, Bartolomé: Azul. Revista de Ciencias y Letras, Azul, Buenos Aires, I, 5, julio-agosto de 1930 , págs. $179-182$.

25 Infesta: "Propiedad rural en la frontera..." y La pampa criolla... 
Andrés de Giles, San Miguel del Monte y Luján, cuyos destinatarios fueron especialmente pequeños-medianos propietarios y productores rurales, entendidas como una estrategia colonizadora efectuada por el rosismo para incrementar su base política en la región mediante el amparo de estos sectores sociales. ${ }^{26}$ De hecho, si bien la colonización de las fronteras internas a través de donaciones sistemáticas de tierras funcionó como aliciente para el establecimiento de pobladores, constituyó, entre otras, una de las políticas formales básicas desarrolladas durante el proceso de construcción del Estado y la Nación en la segunda mitad del siglo XIX, tanto en la Argentina como en otras regiones de América, su existencia durante la primera mitad se advierte especialmente durante el período de gobierno de Juan Manuel de Rosas. ${ }^{27}$

Las suertes de estancia concedidas en Azul se plantearon con una extensión de media legua de frente por legua y media de fondo, equivalente a 2.025 has. cada una, medida que, según los parámetros tecnológicos del momento, permitía cubrir las necesidades de reproducción de una familia de pobladores de la campaña dedicada especialmente a la cría del ganado vacuno..$^{28}$ Esta superficie es mayor a la media encontrada en una zona del norte de la campaña bonaerense como San Nicolás, donde prevaleció la franja 0-499 has. hacia mediados del siglo XIX, pero tras un proceso de fragmentación comenzado a principios del siglo XVIII. Y, aunque ubicada en el centro del paradigma del "gran latifundio pampeano", la frontera sur es una superficie menor en comparación con otros partidos de antigua colonización como Chascomús, Ranchos y Monte, con un promedio general de 3.731 has. hacia 1850, dentro de un proceso colonizador iniciado a fines del siglo XVIII. Y también en contraste con otros partidos del mismo "nuevo

26 Garavaglia: "La propiedad de la tierra...". Gelman: "Unitarios y Federales...".

27 Garavaglia: "La propiedad de la tierra...". Halperín Donghi, Tulio: Una Nación para el desierto argentino, CEAL, Buenos Aires, 1982. Véase, por ejemplo, el caso de la colonización agraria mixta de Santa Fe en Gallo, Ezequiel: La Pampa gringa. La colonización agraria en Santa Fe (18701895), Sudamericana, Buenos Aires, 1983. Por otro lado, en Brasil la colonización del oeste paulista se llevó a cabo por pobladores rurales inmigrantes, fundamentalmente provenientes del sur de España e Italia, que se articularon al ciclo productivo del café y se vieron beneficiados por políticas precisas de fomento de la inmigración realizadas por el Estado. Véase González Martínez, Elda E.: Café e inmigración. Los españoles-Sao Pablo 1880-1930, Cedeal, Madrid, 1990 e "Identidad y representación colectiva de un grupo inmigrante: los españoles en Sao Paulo. 1950-1970”, en González, Elda; Moreno Alfredo; Sevilla, Rosario (Edits.): Reflexiones en torno a quinientos años de Historia de Brasil, Editorial Catriel, Madrid, 2001. "Una revisión de las diversas políticas estatales sobre la colonización de las fronteras internas y los procesos de conformación de los Estados republicanos en Iberoamérica" en Lanteri: "Estado, tierra y poblamiento...”, especialmente "Introducción”, págs. 1-14.

28 Garavaglia: Pastores y labradores... y "La propiedad de la tierra...". 
sur”, Dolores registró un promedio cercano (2.591,4 has. en más del $50 \%$ de los individuos con tierra para 1840). pero con un proceso de asentamiento iniciado en las primeras décadas del siglo XIX y Tandil, que presentó un tamaño promedio de superficie mucho mayor, de 17.037 has. hacia la misma fecha. ${ }^{29}$ Sin embargo, las suertes son de dimensiones enormes si las comparamos con otras regiones fronterizas de América, como Brasil, Estados Unidos o la Amazonia andina, pero cabe destacar que, en términos comparativos con el interior de la campaña de Buenos Aires, con otras modalidades de traspaso de tierras fiscales de la zona y en el marco de las condiciones tecnológicas y de acceso a los mercados contemporáneos, constituyen superficies de pequeñas-medianas dimensiones, que en ese momento sólo permitían cubrir la reproducción agraria familiar. ${ }^{30}$

Para obtener los títulos de propiedad de las suertes los pobladores debían cumplir con un conjunto de pautas y condiciones que se detallan en el decreto de septiembre de 1829, entre las que contaban: poblarlas con su familia o personas de faena, hacerlo al cabo de un año con un capital no menor al de cien cabezas de ganado vacuno o su equivalente en equino o capital agrícola, levantar un rancho de paja y construir un pozo de balde, entre otras. Los otorgamientos, así como la delimitación y ubicación de los terrenos y las concesiones de los títulos de propiedad, estuvieron a cargo del comandante general de la campaña, que en ese entonces era Juan Manuel de Rosas. ${ }^{31}$

29 Canedo, Mariana: Propietarios, ocupantes y pobladores. San Nicolás de los Arroyos, 1600 1860, Grupo de Investigación en Historia Rural Rioplatense, Universidad Nacional de Mar del Plata, Buenos Aires, 2000, págs. 212-213. Banzato, Guillermo: "Análisis y comentario de fuentes para el estudio de la propiedad de la tierra en los partidos de Chascomús, Ranchos y Monte, 1779-1850", Trabajos y comunicaciones ( $2^{a}$ Época), Facultad de Humanidades y Ciencias de la Educación, Universidad Nacional de La Plata, Buenos Aires, 25, 1999, pág. 167. Mascioli: "Caminos de acceso al usufructo...", pág. 89. Mosse, Valeria: "La propiedad de la tierra en la frontera sur de Buenos Aires. El caso de Tandil visto a través de los duplicados de mensura", CD de las IX Jornadas Interescuelas/Departamentos de Historia, Universidad Nacional de Córdoba, Córdoba (Argentina), 2003, pág. 6.

30 Dean, Warren: Rio Claro. A Brazilian Plantation System, 1820-1920, Stanford University Press, Stanford, California, 1976. Holloway, Tomas H.: Inmigrants on the Land. Coffee and Society in Sao Pablo, 1886-1934, The University of North Carolina Press, USA, 1980. White, Richard: "It's your misfortune and none of my own”... García Jordán, Pilar (Coord.): La construcción de la Amazonía andina (Siglos XIX-XX). Procesos de ocupación y transformación de la Amazonía peruana y ecuatoriana entre 1820 y 1960, Colección Abya-Yala 18, Ediciones Abya-Yala, Quito, 1995. Sala i Vila, Nuria: Selva y Andes. Ayacucho (1780-1929) Historia de una región en la encrucijada, Biblioteca de Historia de América, 22, CSIC, Madrid, 2001.

31 AHPBA, La Plata, Sala de Representantes: Registro Oficial del Gobierno de Buenos Aires, 1829, pág. 17. 
Asimismo, el gobierno dictaminó que la extensión del título de propiedad se daría luego de que los pobladores presentasen un documento concedido por el comandante en el que se debía establecer el correcto cumplimiento de las condiciones impuestas por el decreto de 1829 para poder obtenerlo y que podrían disponer de sus terrenos con libertad luego de diez años de haberlos poblado. Además del aliciente de la entrega de terrenos en propiedad para poblar el lugar, el gobierno estableció que las familias que se asentaran en esa línea de fronteras estarían exentas de realizar el servicio militar, excepto la defensa de la zona de su poblamiento.

En junio de 1832, Juan Manuel de Rosas, entonces gobernador de la provincia de Buenos Aires, basándose en el decreto anterior, estableció la necesidad de llevarlo a cabo debido a las condiciones de pobreza que el levantamiento de diciembre de 1828 y la sequía de 1829-1832 habían producido en la población rural. Por medio de un nuevo decreto, el gobierno dictaminó la voluntad de establecer una población regular en Azul y propuso la anulación de los derechos de los enfiteutas de la región a cambio de una o dos suertes de estancia en propiedad, que serían otorgadas según el decreto de 1829. Además, se estableció que no se admitirían más denuncias de pobladores y se otorgaron cuatro leguas de tierra para la construcción del ejido del pueblo, sin permitir que fuesen disputadas por ellos. Ante la falta de un juez, el gobierno nombraría a una persona encargada de distribuir los terrenos para los ejidos de Azul y las guardias Argentina, Blanca y Mayo. ${ }^{32}$

Ahora bien, más allá de las disposiciones oficiales respectivas, ¿cuántas suertes fueron donadas por el Estado? ¿Qué características presentó su proceso de poblamiento? ¿Quiénes fueron los pobladores beneficiados por esta política? Veamos.

En primer lugar, hemos identificado que el gobierno rosista cedió 305 suertes de estancia a 296 particulares a partir de 1832; es decir, un total aproximado de 617.625 has. de tierras públicas que fueron concedidas por el Estado mediante esta modalidad. Los ritmos de ocupación y de apropiación fueron muy rápidos y se corresponden especialmente con la duración el período de gobierno de Rosas. El mayor porcentaje de poblamiento de las suertes se dio en la década de 1830, concentrado en el primer lustro del decenio. Luego la tendencia continúa pero merma significativamente,

32 Muzlera, Joaquín M.: Recopilación de Leyes, Decretos y Resoluciones de la Provincia de Buenos Aires sobre Tierras públicas, desde 1810 a 1895, Editor Isidro Solá Sans, La Plata, (s/f), Tomo I. 
tal vez porque muchas de las tierras ya estaban ocupadas. Sin embargo, algunas suertes fueron abandonadas y otras vueltas a poblar durante el período, debido a malones indígenas, mientras otras fueron embargadas por el rosismo. ${ }^{33}$

En segundo lugar, el proceso de ocupación y de apropiación de las suertes presentó límites muy lábiles. Desde el mismo momento en que fueron adjudicadas por el Estado y violando las disposiciones oficiales que prohibían la enajenación entre particulares antes de la escrituración, comenzaron a ser traspasadas entre éstos predominantemente mediante la compra-venta y herencia. De hecho, si bien recién a partir de 1860 las suertes comenzaron a ser escrituradas por los donatarios, sus descendientes u otros pobladores, fueron ocupadas, apropiadas y en algunos casos traspasadas por sus beneficiarios durante el período. Otra característica distintiva es la rápida puesta en producción de los terrenos. Desde el mismo momento de su ocupación, los pobladores fueron estableciendo distintas clases de instalaciones agrarias y mejoras en su interior, como estancias, chacras, postas, etc., que remiten a las actividades productivas agrícola-ganaderas y comerciales desarrolladas, y que fueron también, eventualmente, objeto de transferencias entre particulares. ${ }^{34}$

En tercer lugar, los donatarios presentaban un perfil socio-demográfico y económico bastante similar al resto de la población de Azul, aunque pareciera ser que en conjunto tuvieron mayor capacidad de acumulación. Fueron, en general, pequeños y medianos productores agrarios dedicados especialmente a la cría del ganado vacuno. Un pequeño grupo estuvo estrechamente vinculado con el gobernador Rosas por relaciones de parentesco consanguíneo, ritual o de corte político, como su hijo Juan, su hermano Prudencio, los Burgos, los Miñana, los Guerrico, entre otros. ${ }^{35}$

33 Lanteri, Ma. Sol: "Poder, poblamiento y relaciones interétnicas en el sur bonaerense. Las donaciones de tierra en el arroyo Azul en la primera mitad del siglo XIX", tesis de licenciatura, Facultad de Humanidades, Universidad Nacional de Mar del Plata, Buenos Aires, 2000 y "Pobladores y donatarios en una zona de la frontera sur durante el rosismo. El arroyo Azul durante la primera mitad del siglo XIX", Quinto Sol, Revista de Historia Regional, 6, 6, Instituto de Estudios SocioHistóricos, Facultad de Ciencias Humanas, Universidad Nacional de La Pampa, La Pampa, 2002, págs. 11-42.

34 Lanteri: "Pobladores y donatarios..." y "Poblamiento, producción y relaciones interétnicas en la frontera sur bonaerense. Azul, 1832-1860", VIII Jornadas Interescuelas y Departamentos de Historia, Salta, 2001.

35 Ibídem. Sobre la estructura de la propiedad rural en Azul véase Infesta: "Propiedad rural en la frontera...". 
Con todo, si bien las suertes fueron ocupadas, apropiadas y puestas en producción por sus pobladores, no pudieron ser escrituradas en su mayoría porque a partir de 1839 el gobierno prohibió el traspaso de tierras públicas a particulares excepto las comprendidas por los boletos de premios de 1839, que beneficiaron a aquellos que permanecieron fieles a la causa rosista luego del levantamiento de los "Libres del Sud". ${ }^{36}$ Esto provocó que recién a partir de la década de 1860 y especialmente luego de la ley de arrendamientos rurales de 1857 — por medio de la cual el Estado permitía la regularización de los tenedores precarios de tierras públicas- comenzaran a escriturar sus tierras. Es decir, que a pesar de que la mayoría de los donatarios cumplió con las condiciones de poblamiento y defensa de la frontera estipuladas por el gobierno rosista, sólo tres pobladores con lazos cercanos a él fueron propietarios legales de sus suertes, que escrituraron en 1839: Prudencio y Juan Rosas (hermano e hijo del gobernador respectivamente como ya mencionamos) y Mariano Lara. ${ }^{37}$ Aunque esta situación no impidió que los donatarios pudieran usufructuar las tierras, generar derechos de ocupación, ni que fueran considerados como "propietarios" por el Estado durante la primera mitad del siglo XIX, dentro de una coyuntura donde el concepto moderno de propiedad privada estaba todavía en cierne, y que no hubieran pagado, en algunos casos, el impuesto a la propiedad de la contribución directa. ${ }^{38}$

Por otro lado, aunque en Azul se registra la presencia de poblamiento espontáneo previo al impulso colonizador oficial, las donaciones contribuyeron a aumentar su establecimiento. El crecimiento más pronunciado se produjo en las décadas de 1830-1850, coherente con el proceso de ocupación de las suertes de estancia, y susceptible de ser comparado con

36 Infesta: "Tierras, premios y donaciones...".

37 Infesta: "Propiedad rural en la frontera...", pág. 273, también confirmado por nuestros datos.

38 Archivo General de la Nación (AGN), Buenos Aires, X, 25-4-6: "Padrón de haciendas y suertes de Estancia pertenecientes al Fuerte Azul y a los capitalistas que han pagado la Contribución Directa hasta el año pasado de 1836". Agradezco al Dr. Carlos O. Cansanello (UNLu-UBA) por haberme llamado la atención sobre esta fuente. Lanteri, Ma. Sol: "La tierra y el poblamiento en una zona de la frontera sur bonaerense durante la primera mitad del siglo XIX. El arroyo Azul y el rol de las políticas estatales", $C D$ de las IX Jornadas Interescuelas/ Departamentos de Historia, Universidad Nacional de Córdoba, Argentina, 2003. Sobre la importancia de las prácticas consuetudinarias en el acceso a la tierra y la construcción del concepto de propiedad privada en la campaña bonaerense véase Fradkin, Raúl: “Según la costumbre del İPays'...” y "Entre la ley y la práctica: la costumbre en la campaña bonaerense de la primera mitad del siglo XIX”, Anuario del IEHS, 12, UNCPBA, Tandil, 1997, págs. 141-156. Sobre el impuesto de la contribución directa ver Gelman, Jorge; Santilli, Daniel: "Distribución de la riqueza y crecimiento económico. Buenos Aires en la época de Rosas", Desarrollo Económico, Buenos Aires, Vol. 43, 169, abril-junio de 2003, págs. 75-101. 
las áreas de poblamiento más exitoso de la campaña rioplatense, como las primeras etapas colonizadoras de San Nicolás o el oriente entrerriano ${ }^{39} \mathrm{La}$ tasa de crecimiento porcentual anual indica la cifra del 4,1\% entre 1838 y 1854, con escasa variación del espacio ocupado. Para el período 18541869 el guarismo disminuye a $1,33 \%$, lo que refiere que el mayor porcentaje de población se estableció en la zona durante el período rosista. Según la información de los padrones, que no registran a la población indígena con territorialidad en la región, la población censada de Azul se agrupa principalmente en unidades censales (UC) de tamaño pequeño y mediano. La media encontrada es de 7,9 personas en 1836 y 7,88 en 1838, la moda es de 4 para ambas fechas y la mediana de 6 y 5 personas respectivamente. Más del $50 \%$ de la población en estos dos años apareció nucleada en torno a UC integradas por 1-10 personas. ${ }^{40}$ Es decir, que en plena frontera sur, espacio frecuentemente considerado de grandes unidades de propiedad-producción, se registra la presencia predominante de unidades de dimensiones mucho más cercanas al trabajo agrario familiar que a otras formas de dependencia laboral típicas de una gran instalación rural, inclusive en las primeras décadas del siglo XIX.

Sin embargo, este predominio de UC de tamaño pequeño y mediano, que también se encontró en otros partidos del "nuevo sur", no impidió la concentración de población en otras grandes unidades. Por citar algunos ejemplos, las tres UC de los "hacendados" Prudencio Rosas, el mismo gobernador Juan Manuel de Rosas y su primo, Nicolás Anchorena, acapararon juntas el 11,2\% del total poblacional de Azul en 1836 y el 22,3\% en 1838. Es decir, que a diferencia de la época colonial, cuando la característica central de estos agrupamientos en la campaña bonaerense era el predominio de UC pequeñas y medianas, en la década de 1830 coexistieron éstas con otras muy grandes unidades. ${ }^{41}$

Habiendo analizado entonces las políticas desarrolladas por el Estado para colonizar la frontera sur desde el período tardo-colonial y destacado el

39 Canedo: Propietarios, ocupantes... Schmit, Roberto: "Población, migración y familia en el Río de la Plata. El oriente entrerriano, 1820-1850”, Anuario del IEHS, 15, UNCPBA, Tandil, 2000, págs. 289-313.

40 Lanteri: "Poder, poblamiento y relaciones interétnicas..." y "Pobladores y donatarios...".

41 Ibídem. Gelman, Jorge: "Crecimiento agrario y la población en la campaña bonaerense durante la época de Rosas. Tres partidos del Sur en 1839", Cuadernos del Instituto Ravignani, 10, UBA, Buenos Aires, 1996 y "Unos números sorprendentes. Cambio y continuidad en el mundo agrario bonaerense durante la primera mitad del siglo XIX”, Anuario del IEHS, 11, UNCPBA, Tandil, 1996, págs. 123-145. 
papel que tuvo el gobierno rosista en el poblamiento de Azul mediante la modalidad de las donaciones de suertes, las reglamentaciones oficiales y las características centrales del proceso, en el próximo apartado nos abocaremos al estudio comparativo de las distintas formas de adjudicación de tierras fiscales en la zona.

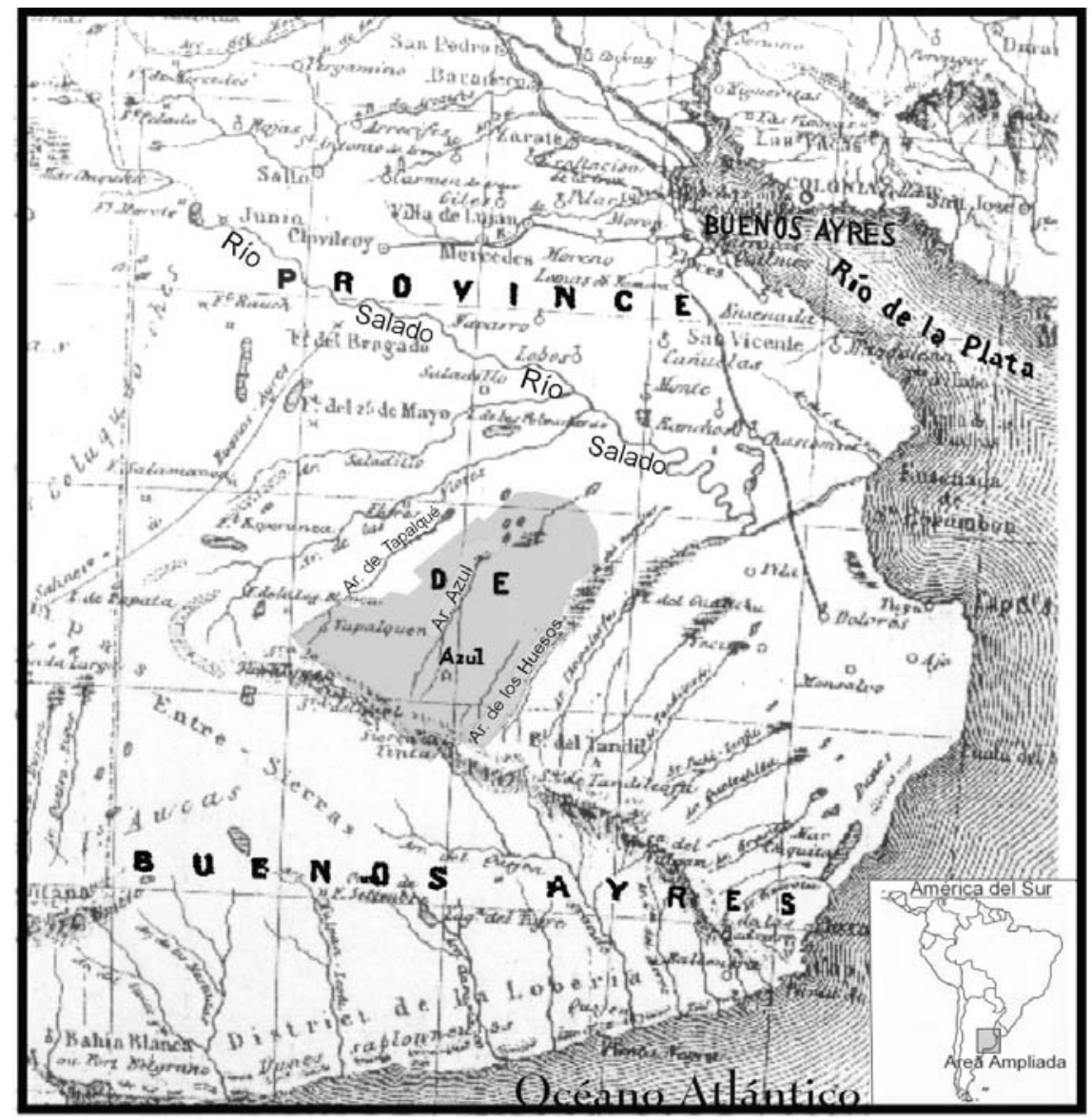

Fuentes: Elaboración propia sobre la base del mapa de d'Orbigny, Alcide: Carte de la Conféderation Argentina. Divisée en ses defférence provinces et territoires et des Pays voisins: État Oriental de l'Uruguay, partie du Brésil et de la Bolivie, primera mitad del siglo XIX (fragmento) y a DGYC, Registro Gráfico de la provincia de Buenos Aires de 1864. 


\section{Las modalidades de cesiones de tierras fiscales en el Azul}

Durante el período abordado, además de las donaciones de suertes, el Estado implementó diferentes formas de traspaso de la tierra pública a manos de particulares que fueron comunes con otros partidos de la campaña bonaerense. Si bien ninguna modalidad manifestó la magnitud que tuvieron las donaciones, a continuación veremos en qué consistió cada una para luego poder compararlas en conjunto.

\section{CUADRo 1}

REGISTRO DE ENFITEUSIS

\begin{tabular}{lccc} 
Décadas & N de Traspasos & N de Has. & $\%$ \\
\hline $1821-1830$ & 5 & 169.506 & 44,8 \\
$1831-1840$ & 8 & $208.475,1$ & 55,1 \\
$1841-1850$ & - & - & - \\
$1851-1860$ & - & - & - \\
\hline Totales & 13 & $377.981,1$ & 100
\end{tabular}

Fuentes: DGYC, Duplicados de Diligencias de Mensura de Azul 1-436; AHPBA, Expedientes de Escribanía Mayor de Gobierno de la Provincia de Buenos Aires, números varios; DGYC, Registro de arrendamientos y enfiteusis ventas 1818-1838, Dirección de Geodesia, Asesoría Histórica, 229; DGYC, Libro de enfiteusis 1825-1840, Dirección de Geodesia, Asesoría Histórica, 223 y DGYC, Registro Gráfico de la Provincia de Buenos Aires de 1864.

\section{CUADRo 2}

REGISTRO DE ARRENDAMIENTOS

\begin{tabular}{cccc}
\multicolumn{1}{c}{ Décadas } & N de Traspasos & N de Has. & $\%$ \\
\hline $1821-1830$ & - & - & - \\
$1831-1840$ & - & - & - \\
$1841-1850$ & - & - & - \\
$1851-1860$ & 3 & 43.497 & 100 \\
\hline Totales & 3 & 43.497 & 100
\end{tabular}

Fuentes: Ibídem cuadro 1 
¿Qué nos muestran los cuadros 1 y 2? En primer lugar, comprobamos que la mayoría de las tierras fiscales transferidas en usufructo en Azul se realizó mediante la enfiteusis y no por arrendamiento, que fue casi irrisorio, tanto en cantidad de traspasos como en volumen de tierras concedido, aunque cabe destacar que éste recién comenzó a desarrollarse hacia finales de la década de 1850. La enfiteusis, implementada desde las "reformas rivadavianas" en 1822 hasta su suspensión en 1840, permitía obtener el usufructo de superficies de tamaño considerable a muy bajo costo, fue una de las vías principales que contribuyeron a la consolidación de la gran propiedad en la campaña bonaerense, especialmente a partir de la ley de ventas de 1836, que permitió su apropiación legal..$^{42}$ Por su parte, el arrendamiento fue la forma de traspasos de tierras desarrollada por el Estado de Buenos Aires a partir de la ley de 1857, y lejos de generar una concentración territorial, contribuyó a compensar la situación jurídica de los ocupantes precarios de tierras públicas y a ampliar su ocupación productiva en la provincia en la segunda mitad del siglo XIX. ${ }^{43}$ Empero, si bien el Estado usufructuó más de ocho veces más de tierra pública en enfiteusis que en arrendamiento durante el lapso considerado, Azul sólo registra el 9,1\% del total de la superficie transferida en este sector de la campaña mediante esta primera modalidad, cifrado en 1.543,04 leguas cuadradas, donde las zonas demandadas más importantes fueron Tandil, Monsalvo y Bahía Blanca. ${ }^{44}$

Cabe destacar que de los trece traspasos en enfiteusis, cuatro fueron luego anulados porque ocupaban el área donde se realizaron las donaciones de las suertes, a pesar de que no tenemos información de que estos enfiteutas hayan sido compensados con ellas tal como estableció el decreto de 1829. Además siete solares fueron comprados en propiedad plena al Estado por parte de particulares a partir de 1836. Mientras que de las tres transferencias en arrendamiento, una fue una renovación de una superficie que ya se encontraba en enfiteusis en la década de 1830. La superficie media de

42 Infesta: "La enfiteusis en Buenos Aires...".

43 Valencia, Marta: "Las tierras de Buenos Aires: el sistema de arriendo público. 1857-1876", Trabajos y comunicaciones ( $2^{a}$ Época), 25, Facultad de Humanidades y Ciencias de la Educación, Universidad Nacional de La Plata, Buenos Aires, 1999, págs. 179-216; "Las tierras de Buenos Aires: del arriendo público a la propiedad privada. 1864-1876", en Lázaro, Silvia (Coord.): Estado y cuestiones agrarias en Argentina y Brasil: Políticas, impactos y procesos de transformación, Facultad de Humanidades y Ciencias de la Educación, Universidad Nacional de La Plata, Buenos Aires, 2000, págs. 149-194 y "Las tierras públicas de Buenos Aires: políticas y realidades en la segunda mitad del siglo XIX", Anuario del Centro de Estudios Históricos "Profesor Carlos S. A. Segreti", 1, 1, Córdoba (Argentina), 2001, págs. 113-128.

44 Infesta: "La enfiteusis en Buenos Aires...". 
los terrenos enfiteúticos fue de 29.075,5 has., mientras que la de las tierras en arrendamiento fue de 14.499 has., ambas de grandes dimensiones en comparación al tamaño de las suertes.

Por otro lado, comprobamos que el mayor porcentaje de las transferencias y del volumen de tierras concedidos en Azul se realizó mediante su entrega en propiedad; plena, en el caso de las ventas y condicionada, en el caso de las suertes.

\section{CuAdro 3}

REGISTRO DE VENTAS

\begin{tabular}{lccc} 
Décadas & N de Traspasos & N de Has. & $\%$ \\
\hline $1821-1830$ & - & - & - \\
$1831-1840$ & 10 & $197.000,1$ & 100 \\
$1841-1850$ & - & - & - \\
$1851-1860$ & - & - & - \\
\hline Totales & 10 & $197.000,1$ & 100
\end{tabular}

Fuentes: Ibídem cuadro 1

\section{Cuadro 4}

REGISTRO DE DONACIONES

\begin{tabular}{lccc} 
Décadas & N de Traspasos & N de Has. & $\%$ \\
\hline $1821-1830$ & - & - & - \\
$1831-1840$ & 302 & 611.550 & 100 \\
$1841-1850$ & - & - & - \\
$1851-1860$ & - & - & - \\
\hline Totales & 302 & 611.550 & 100
\end{tabular}

Fuentes: Ibídem cuadro 1; DGYC, Cornell, Juan: "Informe dirigido al Sr. Ministro de Gobierno en el que se da cuenta haber desempeñado Don Juan Cornell la comisión de que fue encargado para el Partido Arroyo Azul", en Libros de Suertes del Arroyo Azul 1832-1880, Dirección de Geodesia, Asesoría Histórica, 162 (bis), 1859 y DGYC, "Plano del Partido Arroyo Azul construido por el Sargento Mayor Don Juan Cornell. Octubre de 1859”, 1270-29-3. 
¿Qué nos muestran los cuadros 3 y 4 ? Como se puede observar, las ventas y donaciones superan con creces a las tierras que fueron cedidas en usufructo. De las diez transferencias en venta, siete casos, como destacamos, corresponden a terrenos que ya se encontraban usufructuados en enfiteusis anteriormente y que fueron comprados por particulares al Estado según la ley de 1836 y el decreto de 1838 , que estableció que aquellos enfiteutas que no compraran sus tierras perderían sus derechos. Las tres restantes corresponden a tres suertes de estancia que, si bien fueron donadas por el gobierno rosista, fueron adquiridas en propiedad particular y por lo tanto restadas del total de las donaciones. Vale decir otra vez que los únicos propietarios legales de las suertes hasta 1860 fueron la familia Rosas y Mariano Lara, que vendió a Prudencio su suerte en 1839.

Por su parte, las donaciones de suertes de Azul constituyeron tanto la mayoría del número de traspasos como el mayor volumen de tierra concedido, no sólo en propiedad, sino de todas las modalidades de tierras fiscales otorgadas a particulares durante el período. Recordemos que la superficie media de ellas fue de 2.025 has. cada una, mientras los terrenos en venta implicaron un promedio mucho mayor, 27.275,1 has., que se corresponde con las grandes superficies enfitéuticas que pasaron a la propiedad plena por medio de esta vía.

Si comparamos en conjunto lo sucedido con cada modalidad al final del período que nos concierne, el panorama es el siguiente:

\section{CUADRO 5}

REGISTRO DE LA CANTIDAD TOTAL DE TRASPASOS DE TIERRAS FISCALES A PARTICULARES SEGÚN DÉCADA Y MODALIDAD

\begin{tabular}{lcccccc}
\multicolumn{1}{c}{$\begin{array}{c}\text { Usufructo } \\
\text { Décadas }\end{array}$} & Enfiteusis & Arrendamiento & Ventas & Doniedad \\
& Donaciones & Totales & $\%$ \\
\hline $1821-1830$ & - & - & - & - & - & - \\
$1831-1840$ & 2 & - & 10 & 302 & 314 & 99,4 \\
$1841-1850$ & - & - & - & - & - & - \\
$1851-1860$ & - & 2 & - & - & 2 & 0,6 \\
\hline Totales & 2 & 2 & 10 & 302 & 316 & 100 \\
\hline & & & & & &
\end{tabular}


ESTADO, TIERRA Y POBLAMIENTO EN LA CAMPAÑA SUR DE BUENOS AIRES

\section{CuAdro 6}

REGISTRO DEL VOLUMEN TOTAL DE TIERRAS FISCALES CEDIDO A PARTICULARES SEGÚN DÉCADA Y MODALIDAD (EN HAS.)

\begin{tabular}{lcccccc} 
Décadas & \multicolumn{2}{c}{$\begin{array}{c}\text { Usufructo } \\
\text { Enfiteusis }\end{array}$} & $\begin{array}{c}\text { Prrendamiento } \\
\text { Ventas }\end{array}$ & Donaciones & $\begin{array}{c}\text { Totales } \\
\text { (Has.) }\end{array}$ & $\%$ \\
\hline $1821-1830$ & - & - & - & - & - & - \\
$1831-1840$ & 43.281 & - & $197.000,1$ & 595.350 & $835.631,1$ & 96,3 \\
$1841-1850$ & - & - & - & - & - & - \\
$1851-1860$ & - & 32.400 & - & - & 32.400 & 3,7 \\
\hline Totales & 43.281 & 32.400 & $197.000,1$ & 595.350 & $868.031,1$ & 100
\end{tabular}

Fuentes: Ibídem cuadros 1-4

\section{GRÁFICO 1}

REGISTRO DEL VOLUMEN TOTAL DE TIERRAS PÚBLICAS CEDIDO A PARTICULARES EN AZUL ENTRE 1820-1860 SEGÚN MODALIDAD DESAGREGADA

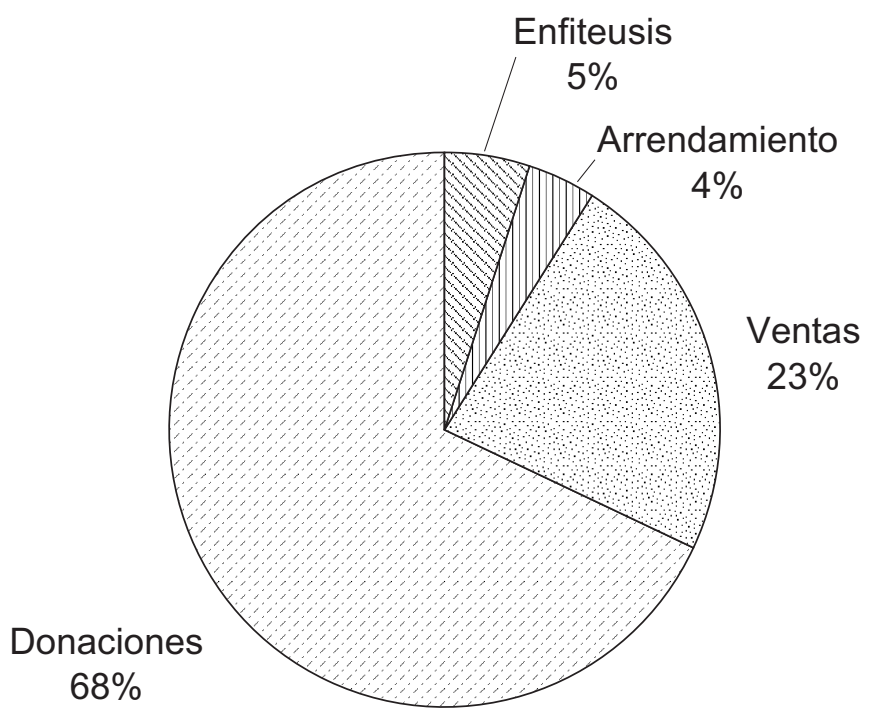

Fuentes: cuadro 6 
Como se observa, el impacto de la política de tierras rosista en Azul fue relevante, ya que si establecemos un corte cronológico por década, comprobamos que la de 1830 nuclea casi la totalidad de los traspasos así como del volumen de tierras fiscales adjudicados por el Estado durante las cuatro décadas abordadas (99,4\% y $96,3 \%$ respectivamente). Asimismo, las donaciones de suertes de estancia constituyeron no sólo la mayor parte del total de las transferencias y del volumen de tierras fiscales cedidos por el Estado en la década de 1830, sino de todo el período, concentrando el $95,6 \%$ de los traspasos y el $68 \%$ del volumen total de tierras otorgado.

Cabe recordar que las transferencias en enfiteusis de la década de 1820 fueron descontadas al final porque fueron anuladas para propiciar las donaciones de suertes y el resto fue comprado en propiedad, por lo que el Estado dejó sin resolver sólo dos parcelas por 43.281 has. Por su parte, las transferencias de la década de 1850 en arrendamiento constituyen únicamente dos casos (el tercero, como mencionamos, ya fue contabilizado en enfiteusis), uno de los cuales se realizó sobre el área de las suertes, por lo que fue descontado del volumen total de las donaciones.

La llamativa ausencia de transacciones en la década de 1840 en todas las modalidades de cesiones de tierras públicas, coherente con la información encontrada para el resto de la campaña de Buenos Aires y entendida, para el caso de la enfiteusis, en el marco de la crítica coyuntura le significó al gobierno de Rosas los múltiples conflictos internos y externos que se sucedieron por esos años. ${ }^{45}$ Por su parte, la década de 1850 también presentó conflictos entre el Estado de Buenos Aires y la Confederación, que se reflejaron en un retroceso importante de la frontera estatal y en la política de tierras, que recién recobraría impulso a partir de la ley de arrendamientos rurales de $1857 .{ }^{46}$

Por otro lado, la media general de superficie para las parcelas en usufructo, si bien varió por década, es mucho mayor a la de los terrenos en propiedad (18.920,25 has. frente a $2.539,6$ has. respectivamente) y el promedio general del período para todas las modalidades de cesiones de tierras fiscales es de 2.746,9 has., situación que se explica por el abultado número de suertes transferido.

¿Qué conclusiones podemos entonces colegir de los datos presentados hasta el momento?

45 Ibídem. Una síntesis de esta coyuntura en Salvatore, Ricardo: "Consolidación del régimen rosista (1835-1852)”, en Goldman: Nueva Historia Argentina..., págs. 323-380.

46 Valencia: "Las tierras de Buenos Aires...". 
En primer lugar, advertimos la importancia que tuvo el gobierno de Rosas en el poblamiento y en la creación de diferentes grupos de propietarios en esta zona de la frontera sur mediante las decisiones políticas generadas en lo concerniente a la entrega de tierras públicas. De hecho, por medio de las donaciones de las suertes y las ventas de 1836 el Estado generó una política dual de beneficio de dos grupos bien diferenciados: por un lado, el de sectores sociales con raigambre colonial en la campaña rioplatense, los pequeños- medianos productores y propietarios rurales, que se beneficiaron con la política de las donaciones, más allá de que un grupo cercano al poder también fue agraciado con ellas. Y por el otro, el de sectores socio-económicos consolidados en la campaña, que pudieron acceder a la propiedad legal de sus explotaciones enfiteúticas, los que, a su vez, estaban estrechamente enraizados en el poder provincial, como Francisco Piñeiro, Félix de Alzaga, Prudencio Rosas, entre otros. Es de destacar que la intención del gobierno provincial con las donaciones de las suertes no fue la de acaparar ingresos para el erario público como en el caso de las ventas, porque sólo se escrituraron tres suertes durante el período; mientras la mayor parte de los beneficiados con esta política pudieron usufructuar sus tierras sin ninguna compensación monetaria al Estado por ello.

En segundo lugar, comprobamos que la mayoría de las tierras adjudicadas fueron transferidas mediante la pequeña-mediana propiedad (condicionada) a través de las suertes de estancia, que constituyeron el significativo 68\% del volumen total de tierras fiscales concedido por el Estado durante ese período (ver gráfico 1). Es decir, que en plena frontera sur, espacio habitualmente considerado de grandes latifundios, no sólo se verifica el predominio abrumador de la pequeña-mediana propiedad frente a la grande, sino que fue el mismo gobierno rosista, tradicionalmente considerado por la historiografía como propiciador del gran latifundio, el responsable de esta política. Y si bien esta coexistencia entre la pequeña-mediana y la gran propiedad también se manifestó en otros lugares de la campaña bonaerense, en ninguno de ellos la presencia de la pequeña tenencia tuvo la envergadura que adquirió en la frontera de Azul, ni tampoco se manifestó desde el inicio de sus procesos colonizadores como en éste, sino que fue el resultado de un proceso de fragmentación secular.

En tercer lugar, la gran concentración de tierras adjudicadas en la década de 1830 nos parece un dato ilustrativo, porque es en ese preciso momento cuando en la campaña se está desarrollando la "expansión ganadera", con el corrimiento estatal hacia el sur de la provincia de Buenos 
Aires, dentro de un marco de aumento de los precios de la tierra y el ganado a partir de $1820 .{ }^{47}$ Por lo tanto se necesita el poblamiento efectivo de esta región, tanto para articular estas tierras al ciclo productivo fundamentalmente ganadero en marcha, así como para consolidar también la soberanía territorial del nuevo Estado provincial en esa zona de frontera con las sociedades indígenas. Asimismo, el inicio de la década de 1830 constituyó una crítica coyuntura en la que se produjo una de las sequías más importantes registradas en la región que afectó a la producción rural y además fue el interregno entre los dos períodos de gobierno de Juan Manuel de Rosas. En efecto, la época de otorgamiento de las donaciones fue concomitante a las disputas entre las distintas facciones federales por el poder porteño, a la campaña militar hasta el río Colorado encabezada por Rosas, al establecimiento de la política del "negocio pacífico de indios", entre otras cuestiones, que contribuyeron al afianzamiento del poder del sector dirigente y propietario que lideró la confederación hasta $1852 .{ }^{48}$ De hecho, los repartos gratuitos de tierras que se plantearían en diferentes lugares de la campaña como una estrategia política para ampliar la base social y neutralizar el avance de los sectores disidentes al rosismo tuvieron en Azul un peso incontrastable: el lugar de enclave por excelencia de su poder militar en la frontera sur, sede del $6 .^{\circ}$ regimiento de milicias de la campaña liderado por el mismo Prudencio Rosas, que junto a los "indios amigos" con territorialidad en la región contribuirían a mantener el statu quo rosista y a defenderlo en algunas situaciones conflictivas, como los malones de 1836-37 y la rebelión de los estancieros de $1839 .{ }^{49}$

Por otro lado, esta concentración de transferencias en la década de 1830 y la abrumadora presencia de las donaciones en Azul conducen a plantearse una comparación con otros procesos colonizadores de la fronte-

47 Halperín Donghi: "La expansión ganadera...”. Garavaglia: Pastores y labradores...

48 Garavaglia: "La propiedad de la tierra en la región pampeana...". Gelman: "Unitarios y Federales...". Un resumen de esta coyuntura en Pagani, Rosana; Souto, Nora; Wasserman, Fabio: "El ascenso de Rosas al poder y el surgimiento de la confederación (1827-1835)", en Goldman: Nueva Historia Argentina..., págs. 283-321. Sobre la política indígena del gobierno véase Ratto, Silvia: "Indios amigos e indios aliados. Orígenes del İnegocio pacífico' en la provincia de Buenos Aires (18291832)", Cuadernos del Instituto Ravignani, 5, UBA, Buenos Aires, 1994, págs. 5-34 y "El `negocio pacífico de indios': la frontera bonaerense durante el gobierno de Rosas", Revista Siglo XIX, 15, México, enero-junio 1994, págs. 25-47.

49 Sobre estos episodios ver Ratto, Silvia: "Soldados, milicianos e indios de 'lanza y bola'. La defensa de la frontera bonaerense a mediados de la década de 1830", Anuario IEHS, 18, UNCPBA, Tandil, 2003, págs. 123-152 y Gelman, Jorge: "La rebelión de los estancieros. Algunas reflexiones en torno a los Libres del Sur de 1839”, Entrepasados, 22, Buenos Aires, 2002, págs. 113-144. 
ra sur. Según los datos hasta el momento, en Dolores, por ejemplo, la mayoría de las transferencias de tierras públicas otorgadas a particulares durante 1800-1860 fue realizada en las décadas de 1820 y 1850 y el mayor volumen de éstas se adjudicó en la década de 1820 mediante la modalidad de la enfiteusis..$^{50}$ Por su parte, en Tandil se produjo un proceso sustancialmente distinto al ocurrido en Azul, en tan sólo tres años, entre 1836 y 1839 , el $80 \%$ de las tierras del partido pasaron a manos privadas. Es decir, que el proceso de apropiación privada plena en este sector tuvo un ritmo vertiginoso y permitió el acceso a la propiedad legal de sectores económicamente consolidados y estrechamente vinculados con el poder provincial, con un predominio claro de la gran propiedad, a pesar de su constante fragmentación a lo largo del siglo XIX. ${ }^{51}$ Además, a diferencia de Azul, en ambas zonas el peso de los premios y las donaciones fue mucho menos significativo y presentó otras características, e implicó un escaso porcentaje del total de las tierras fiscales adjudicadas, del 24,6\% para Dolores y sólo el 3\% para Tandil y en superficies medias mucho mayores. ${ }^{52}$

Mediante las donaciones de las suertes y las ventas de 1836 el Estado benefició a dos sectores sociales bien diferenciados: por un lado, los pequeños-medianos propietarios y productores agrarios y, por el otro, los muy grandes, que estaban además estrechamente vinculados con él, si bien algunos de ellos también fueron agraciados con las donaciones. Sin embargo, la presencia de la pequeña-mediana propiedad, aunque coexistió con otras de grandes dimensiones desde el inicio del proceso colonizador, fue abrumadora frente al resto de las modalidades de tenencia de tierras fiscales, que comprendió las suertes la reveladora cifra del $68 \%$ del total de tierras públicas otorgado en un área caracterizada tradicionalmente como el paradigma del gran latifundio pampeano. La gran concentración del volumen y de las transferencias registrada en la década de 1830 se entiende en el marco de un proceso de expansión agraria vinculado al ciclo del vacuno, de afianzamiento de la soberanía territorial del Estado provincial de Buenos Aires en la frontera interna y de consolidación del orden rosista mediante la captación de diversos sectores sociales. Además, las donaciones condicionadas fueron adjudicadas en Azul, un enclave del poder militar del rosismo en la frontera

50 Mascioli: "Caminos de acceso al usufructo...".

51 Mosse: "La propiedad de la tierra...".

52 Ibídem, pág. 5. Mascioli: "Caminos de acceso al usufructo..." y "Productores y propietarios de la frontera bonaerense. Dolores, 1798-1860", tesis de maestría, Universidad Internacional de Andalucía, Sede Iberoamericana Santa María de la Rábida, Huelva, 1999, pág. 96. 
sur, mientras que en otras áreas de esta misma región el peso de las donaciones y los premios tuvo un impacto mucho menor y presentó otras características, que propició las grandes extensiones de tierra.

Finalmente, cabe contrastar la magnitud de esta política frente a otras modalidades de adjudicación de tierras fiscales desarrolladas por el gobierno de Rosas en la campaña de Buenos Aires. Las donaciones condicionadas, que sólo se efectivizaron en Azul, implicaron la entrega de 228,75 leguas cuadradas en 305 donaciones a 296 particulares, aunque durante la primera mitad del siglo XIX sólo pasaron a la propiedad plena 2,25 leguas cuadradas. Mientras los premios por combate contra los indios y a la fidelidad política sumaron juntos 820,75 leguas cuadradas, de las que fueron escrituradas 192,7 por 27 particulares durante el período, lo que favoreció claramente el desarrollo de la gran propiedad en la región..$^{53}$

\section{Conclusiones}

El objetivo central de este trabajo fue tratar de saldar la carencia de información sobre una de las modalidades de adjudicación de tierras públicas implementada por el gobierno de Rosas en la campaña de Buenos Aires. En gran medida, éste fue tradicionalmente considerado por la historiografía como estrechamente vinculado al sector de los grandes propietarios rurales, con los que se identificó y sustentó las bases de su poder político y económico en detrimento del resto de la población rural y al cual benefició directamente a través de distintas políticas como la de tierras. Si bien éstas, así como otros aspectos concernientes a los caudillismos rioplatenses, están siendo re-examinados en la actualidad, aquí nos detuvimos en una modalidad de traspaso que hasta el momento no había sido objeto de una revisión cuantitativa.

De tal forma, hemos destacado que las donaciones condicionadas de tierras fiscales en propiedad, si bien se plantearon en principio para ser otorgadas en diferentes lugares de la campaña, se efectivizaron en la frontera del arroyo Azul a partir de 1832, y aunque no fue establecido el monto de la oferta estatal, pudimos reconstruir su volumen y compararlo con otras formas de entrega desarrolladas tanto en su interior como en otros lugares de la campaña de Buenos Aires. De hecho, si bien las donaciones

53 Infesta: “Tierras, premios y donaciones...”, págs. 206-207. 
de estas pequeñas-medianas extensiones de tierras públicas no constituyeron la modalidad de otorgamiento predominante efectuada por el rosismo - la que sin dudas contribuyó a fomentar de la gran propiedad en la región, aunque en mucho menor medida de la que tradicionalmente se consideróel impacto cuantitativo que dicha política tuvo en la frontera de Azul fue relevante y se vincula con diferentes aspectos de la coyuntura histórica contemporánea.

Nos preguntábamos en la introducción por qué si desde el período tardo-colonial la tierra había constituido el factor de producción más abundante y accesible en la campaña rioplatense el Estado había implementado esta modalidad, por qué se realizó en Azul, cuáles fueron las características centrales del proceso y cuál la envergadura de esta concesión comparada con otras formas de otorgamiento de tierras fiscales en la región.

Hemos referido que las donaciones de las suertes, junto con las otras modalidades de cesiones del período, fueron realizadas en un contexto de expansión agraria importante en la campaña de Buenos Aires, basada especialmente en el ciclo del vacuno y en un proceso de expansión estatal hacia las tierras del sur del río Salado que, si bien ya había sido planificado por el Estado desde el período tardo-colonial, no había sido exitoso como lo fue durante la primera mitad del siglo XIX. El que ayudó además a consolidar la soberanía territorial del nuevo Estado provincial en construcción frente al espacio ocupado por las sociedades indígenas. De hecho, las donaciones de Azul no sólo contribuyeron a afianzar el área ocupada por el Estado provincial en esta zona de frontera, sino a acrecentarla sustancialmente, ya que la superficie total de las donaciones superó con creces al espacio abarcado con anterioridad por las tierras en enfiteusis de la década de 1820.

Asimismo, si bien las donaciones de suertes en Azul fueron planteadas en 1829, fueron entregadas por el gobernador Rosas recién a partir de 1832, durante el lapso hacia su segundo período de gobierno, que constituyó una crítica coyuntura en la que se estaba fortaleciendo el poder del rosismo, el nuevo sector dirigente y propietario en el litoral, en un marco de disputas al interior del mismo federalismo porteño; cuando además el gobierno implementó diversas acciones como la campaña militar hasta el río Colorado, el establecimiento de su política indígena, entre otras cuestiones. Las donaciones entonces pudieron ser concebidas como una vía para afianzar su poder mediante la captación de determinados sectores sociales, en este caso, los pequeños-medianos propietarios y productores rurales, y fueron establecidas además en un área estratégica de la frontera 
sur como Azul, que junto con el partido contiguo de Tapalqué, constituyeron un foco de su poder militar y los bastiones más fieles a la causa rosista en la región.

Por otro lado, la voluntad política de poblar la frontera sur se materializó con las donaciones que, si bien con asentamientos previos, contribuyeron al establecimiento de población en Azul y a la inmediata puesta en producción de los terrenos por parte de distintos tipos de productores agrarios, especialmente pequeños-medianos dedicados a la producción pecuaria, que acudieron al aliciente de la oferta estatal de tierras. El proceso de poblamiento de Azul fue exitoso, así como también la intención del Estado en el lugar, que se vio compensada por el establecimiento efectivo de pobladores desde el mismo inicio del proceso colonizador oficial, a pesar de algunas coyunturas interétnicas conflictivas.

De hecho, el asentamiento de población en Azul fue concomitante con el período rosista y con la ocupación de las suertes de estancia. A través un rápido ritmo de ocupación, las suertes fueron apropiadas y puestas en producción por parte de sus beneficiarios, que las usufructuaron sin necesidad de una retribución monetaria al Estado por ello -si no mediante otras vías como el servicio miliciano-, ya que sólo tres donatarios escrituraron sus suertes durante la primera mitad del siglo XIX. De esta forma, en Azul se produjo un rápido proceso de apropiación privada de tierras públicas que no fue legal en su mayoría sino hasta después de 1860, cuando se concedieron los títulos formales estipulados desde 1830. Cabe destacar que la intención del Estado mediante las donaciones no fue la de acaparar recursos fiscales para el erario público como en el caso de las ventas de 1836, sino justamente la de contribuir al poblamiento local, a la articulación de las tierras al proceso productivo fundamentalmente pecuario en marcha, al amparo de ciertos sectores de la sociedad rural y al afianzamiento de la soberanía estatal y del orden rosista en la región, que se dieron de forma evidente para el gobierno provincial.

Por otra parte, la información encontrada en el estudio socio-demográfico de la población es coherente con la del registro de la tenencia de la tierra del lugar y refleja una clara articulación del poder en determinados individuos vinculados con los nuevos sectores dirigentes y propietarios en el ámbito rioplatense post-independiente, a la vez que la continuidad de sectores sociales de raigambre colonial en la campaña, los pequeñosmedianos propietarios y productores rurales, que fueron beneficiados directamente con la política de las donaciones, si bien no faltaron algunos 
particulares relacionados con el gobierno que también fueron agraciados con ella.

En efecto, hemos comprobado cómo a diferencia del resto de los partidos de la campaña de Buenos Aires y en especial en un espacio habitualmente considerado como el paradigma de la gran estancia, la frontera sur, en Azul la pequeña-mediana propiedad fue abrumadora frente a la grande, y según la información con que contamos hasta el momento, en ningún otro lugar el impacto de las donaciones fue tan relevante ni presentó estas características. Y hemos advertido además cómo el mismo rosismo, tradicionalmente considerado por la historiografía como propiciador del gran latifundio, fue el responsable de esta política. Aunque también, como destacamos, no dejó de realizar paralelamente su acción predominante, en beneficio de los grandes propietarios de la campaña mediante la ley de ventas de 1836.

Poblamiento efectivo, fortalecimiento de la territorialidad estatal, ampliación del área productiva en la frontera sur, beneficio de diversos sectores sociales, el acceso a las tierras en Azul estuvieron estrechamente vinculados con la participación del Estado provincial de Buenos Aires en la primera mitad del siglo XIX, especialmente durante el gobierno de Juan Manuel de Rosas. La estructura agraria dual entre la pequeña-mediana y la gran propiedad, si bien con un claro predominio de aquélla a diferencia de otras áreas de la frontera sur bonaerense, fue creada por éste y se mantuvo como tal hasta bien entrado el siglo. Cabe ahora, con estos resultados obtenidos como plataforma de análisis, indagar con mayor profundidad sobre la articulación que estos pequeños-medianos productores y propietarios rurales tuvieron en el sustento de las bases del poder del rosismo en esa región clave de la campaña de Buenos Aires. 



\section{Apéndice}

GRÁFICO 1

REGISTRO DEL TOTAL DE TRASPASOS DE TIERRAS PÚBLICAS CEDIDO A PARTICULARES EN AZUL ENTRE 1820-1860 SEGÚN DÉCADA Y MODALIDAD

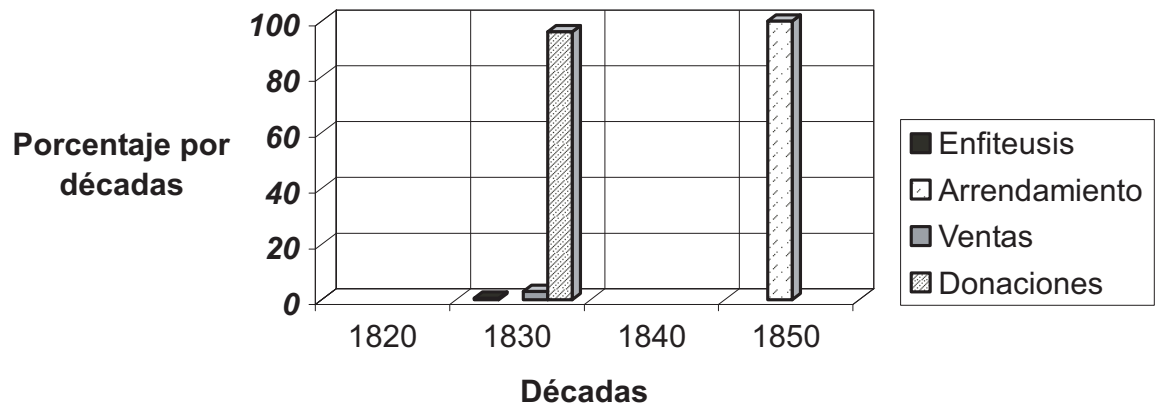

Fuentes: cuadro 5

GRÁFICO 2

REGISTRO DEL VOLUMEN TOTAL DE TIERRAS PÚBLICAS CEDIDO A PARTICULARES EN AZUL ENTRE 1820-1860 SEGÚN DÉCADA Y MODALIDAD

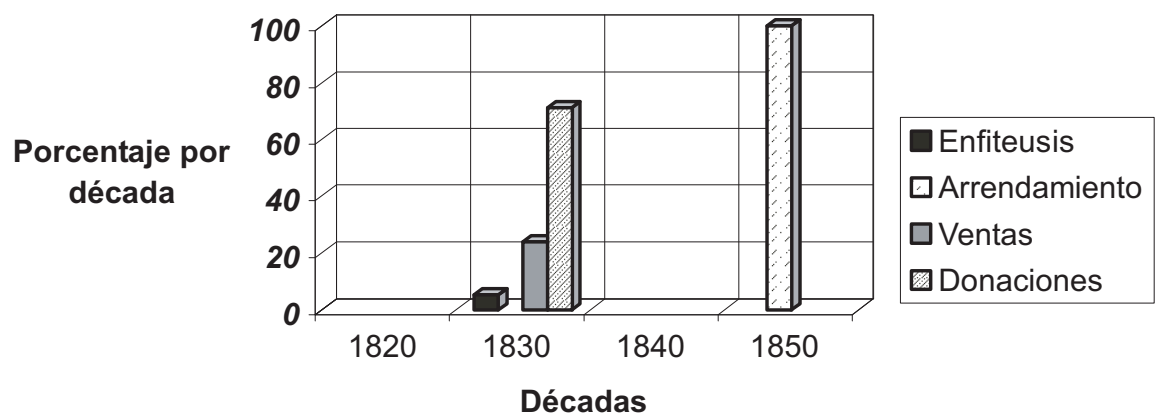

Fuentes: cuadro 6 